\title{
Glycemic Control and Diabetic Complications- Is the Predominant Current Rationale Rational?
}

\author{
Harold E Lebovitz, MD, FACE
}

Professor of Medicine, State University of New York Health Science Center, Brooklyn, US

\begin{abstract}
Summary
Although the level of glycated hemoglobin $\left(\mathrm{HbA}_{1 \mathrm{C}}\right)$ reflects chronic glycemic control, treatment-induced decreases in $\mathrm{HbA}_{1 \mathrm{C}}$ in patients who have established diabetes do not always predict beneficial clinical outcomes. Clinical outcomes are dramatically influenced by the history of previous glycemic control, the extent of current clinical complications, and the side effects of therapeutic agents. Rational approaches to the intensity of glycemic control in individual patients should take these factors into consideration, as well as in setting an appropriate goal for the $\mathrm{HbA}_{1 \mathrm{C}}$ target.
\end{abstract}

\section{Keywords}

$\mathrm{HbA}_{1 \mathrm{C}^{\prime}}$ clinical outcomes, diabetes duration, vascular complications, hypoglycemia

Disclosure: Harold E Lebovitz, MD, FACE, has no conflicts of interest to declare. No funding was received for the publication of this article. Open Access: This article is published under the Creative Commons Attribution Noncommercial License, which permits any noncommercial use, distribution, adaptation, and reproduction provided the original author(s) and source are given appropriate credit.

Received: March 28, 2015 Accepted: April 7, 2015 Citation: US Endocrinology, 2015;11(1):26-7 DOl: http://doi.org/10.17925/USE.2015.11.1.26

Correspondence: Harold E Lebovitz, MD, FACE, Professor of Medicine, State University of New York Health Science Center, Brooklyn, US. E: hlebovitz1@hotmail.com

The level of glycated hemoglobin $\left(\mathrm{HbA}_{1 \mathrm{C}}\right.$ ) has been equated with the rate of development of chronic diabetic vascular complications since the publication of the two classic intervention trials: the Diabetes Control and Complication Trial (DCCT) in patients with type 1 diabetes $^{1}$ and the United Kingdom Prospective Diabetes Study (UKPDS) in patients with type 2 diabetes. ${ }^{2}$ This has been the basis for the standards in guideline recommendations, US Food and Drug Administration (FDA) approval of therapies for diabetes treatment, and the multitude of publications presuming to compare the benefits of different therapies to each other. If these approaches are truly valid, then several facts would need to be true. This commentary examines what those facts are and whether the clinical data support those facts.

\section{The Rate of Development of Chronic Vascular} Complications in Patients with Diabetes Should Be Linearly Related to the Level of $\mathrm{HbA}_{1 \mathrm{c}}$

If this were true, a decrease in $\mathrm{HbA}_{1 \mathrm{c}}$ of $1 \%$ should give the same absolute rate of reduction of vascular complications independent of the baseline $\mathrm{HbA}_{1 \mathrm{C}}$ value. In fact, the DCCT study showed that risk reduction is curvilinear (see Figure 1), with decreases in microvascular complications being greatest at the highest baseline $\mathrm{HbA}_{1 \mathrm{C}}$ values (11\%) and decreasing progressively as baseline $\mathrm{HbA}_{1 \mathrm{C}}$ values approach $7.0 \%{ }^{3}$ The implications of these data are that the greatest clinical benefits are obtained when improving glycemic control in individuals having $\mathrm{HbA}_{1 \mathrm{C}}$ values $\geq 8.0 \%$ and that lowering $\mathrm{HbA}_{1 \mathrm{C}}$ in patients having baseline $\mathrm{HbA}_{1 \mathrm{C}}$ levels $<7.5 \%$ will have modest benefits. Studies showing that one treatment decreases $\mathrm{HbA}_{1 \mathrm{C}} 0.2-0.4 \%$ more than another treatment may not be meaningful in terms of absolute decreases in complications when the resultant values are in the $\mathrm{HbA}_{1 \mathrm{c}}$ range $<7.5 \%$. one might argue that the UKPDS data opposes this concept, because decreasing the median $\mathrm{HbA}_{1 \mathrm{C}}$ from $7.9 \%$ to $7.0 \%$ resulted in a $25 \%$ reduction in microvascular complications. However, the UKPDS study did not analyze the data relative to those having baseline $\mathrm{HbA}_{1 \mathrm{c}}$ levels according to the percentiles of baseline $\mathrm{HbA}_{1 \mathrm{c}}{ }^{2}$ Based on the DCCT data, it is reasonable to presume that the treatment benefits in the UKPDS occurred primarily in those patients in the higher percentiles of baseline $\mathrm{HbA}_{1 \mathrm{C}}$ elevations.

\section{Identical Decreases in $\mathrm{HbA}_{1 \mathrm{C}}$ from the Same Baseline $\mathrm{HbA}_{1 \mathrm{C}}$ Value in Patients with Diabetes Causes the Same Decrease in Vascular Complications}

If this is true, then the decrease in $\mathrm{HbA}_{1 \mathrm{c}}$ itself would be the sole determinant of the benefit of glycemic control. The Epidemiology of Diabetes Interventions and Complications (EDIC) study was a 10-year follow-up of the DCCT cohort after the study completed. At the end of the study (mean 6.5 years) the patients returned to the care of their primary care physicians and returned to the research center once a year for assessment of chronic vascular complications. Within 2 to 3 years, the intensively controlled cohort could not maintain the tight control, and their mean $\mathrm{HbA}_{1 \mathrm{C}}$ increased from $7.3 \%$ to $7.98 \%$. The ordinary control cohort were able to intensify their glycemic control and improved their mean $\mathrm{HbA}_{1 \mathrm{C}}$ from $9.0 \%$ to $8.07 \%$. From year 3 on, both cohorts maintained similar mean $\mathrm{HbA}_{1 \mathrm{C}}$ levels. Despite the same glycemic control, the rates of new microvascular and macrovascular complications were 50-80\% less in the previously intensively controlled cohort than in the previously ordinarily controlled cohort. ${ }^{4,5}$ The EDIC study concludes that the effect of glycemic control on chronic vascular complications in large part depends on previous history of glycemic control. 
Three studies performed in the last decade provide insight into the potential cause of the EDIC results. ACCORD, ${ }^{6}$ ADVANCE, $^{7}$ and VA-DT were large clinical trials that randomized patients with type 2 diabetes who had had previous cardiovascular events or who were at high risk for cardiovascular events to ordinary glycemic control $\left(\mathrm{HbA}_{1 \mathrm{C}}\right.$ 7.3-8.4\%) or intensive glycemic control $\left(\mathrm{HbA}_{1 \mathrm{C}} 6.4-6.9 \%\right)$ and followed them for 3.5-5.6 years for new cardiovascular events. The hypothesis tested was that intensive glycemic control would decrease cardiovascular events. However, the results failed to show any significant decrease in cardiovascular events or any decrease in the progression of clinical microvascular events. The data presented in those three studies suggested that intensive glycemic control had little or no protective effects on the progression of clinically present vascular complications of diabetes.

\section{Low HbA $\mathrm{H}_{1 \mathrm{C}}$ Levels Always Decrease Vascular Complications}

The presumption that lower $\mathrm{HbA}_{1 \mathrm{C}}$ levels always provide better outcomes than higher $\mathrm{HbA}_{1 \mathrm{C}}$ levels seems to be refuted by several studies. It appears that this depends on the methods by which the lower $\mathrm{HbA}_{1 \mathrm{c}}$ levels are obtained. During the ACCORD study, ${ }^{6}$ it became apparent that the cohort in the intensive glycemic control group had a higher mortality than the cohort having moderate glycemic control. Many attempts to discern the mechanism for this increase in mortality have failed to provide a definitive answer. A large retrospective analysis of patients having diabetes and congestive heart failure showed that patients having an $\mathrm{HbA}_{1 \mathrm{C}}<7.3 \%$ had a higher 2-year mortality than those having an $\mathrm{HbA}_{1 \mathrm{C}} \geq 7.3 \%{ }^{8}$ Many intervention, as well as observational, studies have reported that the occurrence of one or more severe hypoglycemic events during treatment appears to increase future mortality and cardiovascular events. ${ }^{9,10}$ Recent demonstrations show that serious hypoglycemia $(<3.1 \mathrm{mmol} / \mathrm{l} ; 56 \mathrm{mg} / \mathrm{dl})$, regardless of whether recognized clinically, is associated with an increase in ventricular arrhythmias in patients having diabetes and clinical cardiovascular disease. ${ }^{11}$ Other studies have shown that hypoglycemia significantly increases the corrected QT interval (QTC). ${ }^{12}$

\section{Conclusions and Recommendations}

Obviously, $\mathrm{HbA}_{1 \mathrm{C}}$ is a reliable measure of glycemic control and a useful tool for assessing chronic management. The problem is that glycemic control itself has been assumed to always determine clinical outcomes. Based on the evidence, it is apparent that this is not true. Equally important to clinical outcomes is the stage of vascular disease at the time of the glycemic control, as well as the nature and severity of side effects of the agents being used to control the glycemia. Aggressive lowering of $\mathrm{HbA}_{1 \mathrm{c}}$ to values between $6.5 \%$ and $7.0 \%$ in patients having minimal vascular disease, by means of agents having minimal side

\section{Figure 1: Retinopathy Progression as a Function of Mean $\mathrm{HbA}_{1 \mathrm{c}}$ During DCCT}
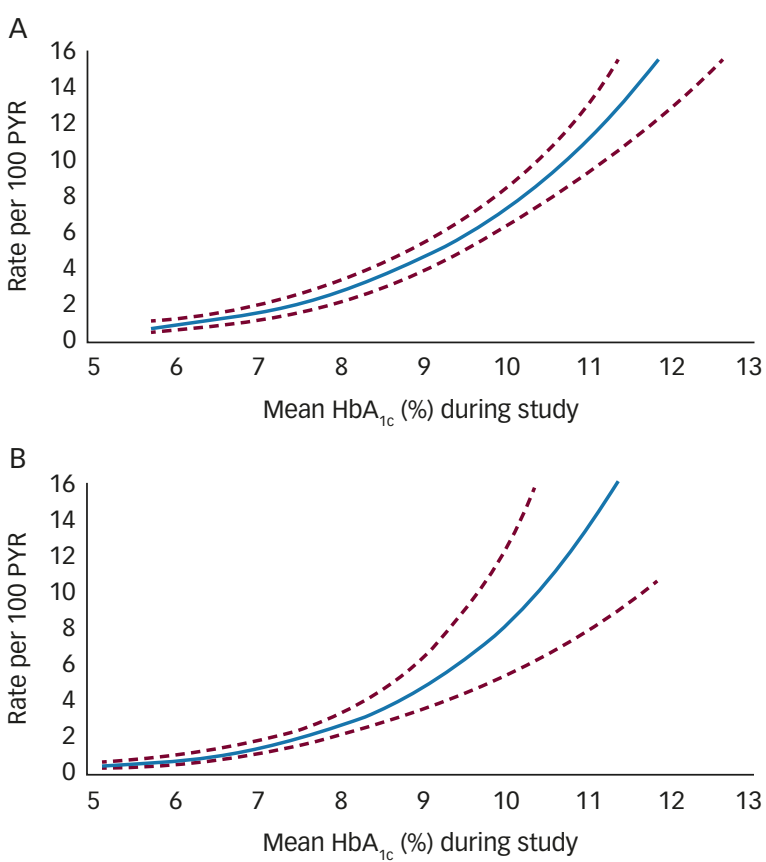

A: Conventional treatment group; $B$ : Intensive treatment group. DCCT $=$ Diabetes Control and Complication Trial; $H b A_{1 c}=$ glycated hemoglobin; $P Y R=$ patient years (Source: Diabetes, 1995;44:968-83). Reprinted with permission of the American Diabetes Association. Copyright 1995

effects, is supported by the available data. By contrast, such aggressive lowering with agents that cause hypoglycemia and weight gain and/or that facilitate fluid retention in patients having diabetes and significant cardiovascular disease or risk for cardiovascular disease has a high likelihood of causing detrimental, rather than beneficial, effects. ${ }^{13}$ In such patients, maintaining glycemic control at a moderate level (7.5\%) using agents that do not cause hypoglycemia or weight gain and that are not detrimental to the cardiovascular system is likely to benefit the patient. What is yet to be determined is whether lowering $\mathrm{HbA}_{1 \mathrm{C}}$ to $7.0 \%$ or lower using agents that have minimal or no metabolic side effects is beneficial to patients having diabetes and significant chronic vascular complications. In evaluating treatment options for glycemic control, it is as important to select therapies by their potential side effects as by their ability to provide a $0.2-0.4 \%$ greater decrease in $\mathrm{HbA}_{1 \mathrm{C}}$. The greatest clinical benefit of an $\mathrm{HbA}_{1 \mathrm{C}}$ target $<7 \%$ is at the onset of diabetes, and the value lessens with increasing duration of poor control. Rational approaches to glycemic control in patients having diabetes are those that improve clinical outcomes and quality of life.
1. The Diabetes Control and Complications Trial Research Group, The effect of intensive treatment of diabetes on the development and progression of long-term complications in insulin-dependent diabetes mellitus, N Eng/ J Med, 1993;329:977-86.

2. UK Prospective Diabetes Study (UKPDS) Group, Intensive blood glucose control with sulphonylureas or insulin compared with conventional treatment and risk of complications in patients with type 2 diabetes (UKPDS 33), Lancet, 1998:352:837-53.

3. DCCT Research Group, The relation of glycemic exposure (HDA1C) to the risk of development and progression of retinopathy in the to the risk of development and progression of retinopathy in the

4. DCCT/EDIC Research Group, Sustained effect of intensive treatment of type 1 diabetes mellitus on development and progression of diabetic nephropathy: the Epidemiology of Diabetes Interventions and Complications (EDIC) Study, JAMA, 2003:290:2159-216
5. DCCT/EDIC Research Group, Prolonged effect of intensive therapy on the risk of retinopathy complications in patients with type 1 diabetes mellitus: 10 years after the Diabetes Control and Complications Trial, Rch Ophthalmol, 2008;126:1707-15.

6. The Action to Control Cardiovascular Risk in Diabetes Study Group, Effects of intensive glucose lowering in type 2 diabetes, N Eng/ J Med, 2008;358:2545-59.

7. The Advance Collaborative Group, Intensive blood glucose control and vascular outcomes in patients with type 2 diabetes, N Engl J Med, 2008:358:2560-72

8. Zounngas S, Patel A, Chalmers J, et al., Severe hypoglycemia and risks of vascular events and death, N Eng/ I Med 2010;363:1410-8

9. Bonds DE, Miller ME, Bergenstal RM, et al., The association between symptomatic, severe hypoglycaemia and mortality in type 2 diabetes: retrospective epidemiological analysis of the ACCORD study, BMJ, 2010;340:B4909

10. Tomova GS, Nimbal V, Horwich TB, Relation between hemoglobin $\mathrm{A} 1 \mathrm{c}$ and outcomes in heart failure patients with and without diabetes mellitus, Amer J Cardiol, 2012;109:1767-73.

11. Stahn A, Pistrosch F, Ganz C, et al., Relationship between hypoglycemic episodes and ventricular arrhythmias in patients with type 2 diabetes and cardiovascular diseases: silent hypoglycemias and silent arrhythmias, Diabetes Care, 2014;37:516-20

12. Beom JW, Kim JM, Chung EJ, et al., Corrected QT interval prolongation during severe hypoglycemia without hypokalemia in patients with type 2 diabetes, Diabetes Metab J, 2013;37:190-5.

13. Currie CJ, Peters RJ, Tynan A, et al., Survival as a function of HbA1C in people with type 2 diabetes: a retrospective cohort study, Lancet, 2010;375:481-9. 